\title{
Reflexiones filosóficas sobre la Independencia y la Revolución
}

\author{
Ambrosio Velasco Gómez
}

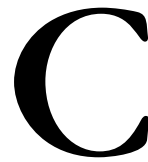

on el propósito de contribuir a una reflexión crítica desde la filosofía sobre la Independencia y la Revolución, y con motivo de sus respectivas conmemoraciones centenarias, el Comité Editorial de Theoría acordó dedicar la sección especial de los números 22 y 23 de la revista a estos temas.

En el número 22 se incluyeron tres artículos sobre la Independencia. El primero de ellos, de carácter eminentemente teórico, de Francisco Colom, titulado "La nación como relato". Los otros dos artículos se ubican históricamente antes y después de la Independencia. Joaquín Rodríguez Beltrán escribe "la identidad como respuesta: un acercamiento retórico-argumentativo a Rusticatio mexicana de Rafael Landívar". Por otra parte, Antolín Sánchez Cuervo analiza las interpretaciones de los filósofos del exilio español sobre el proceso de Independencia.

Francisco Colom se ha destacado en España en la organización de proyectos sobre las independencias iberoamericanas y por ello tiene una visión de conjunto sobre los procesos de emancipación de las naciones del mundo hispanoamericano, incluyendo a la propia España. Con base en esta visión amplia, Francisco Colom se enfoca a analizar, desde un punto de vista histórico y filosófico, la categoría de nación que está implícita en todos los movimientos emancipatorios de principios del siglo XIX en Iberoamérica y que en cada caso particular constituye el fundamento de la justificación política de los Estados independientes. De acuerdo a Colom, la nación es una construcción narrativa que busca integrar y dar identidad a toda una población como sujeto político que aspira o detenta la soberanía. En este sentido, "Las identidades nacionales pueden definirse como estados mentales propiciados por historias, o si se prefiere, una imaginación histórica narrativamente configurada". Colom distingue dos tipos de naciones: la étnica y la civil. La primera está basada en una interpretación del pasado que establece la identidad 
cultural del pueblo, al margen de un poder estatal constituido, mientras que la nación civil se asocia más a la concepción contractualista del liberalismo que instituye la nación como el conjunto de ciudadanos a quienes el poder soberano les reconoce un conjunto de derechos. Estas dos concepciones de nación se relacionan tensionalmente: "por medio de un acto jurídico se crea un sujeto colectivo que toma en sus manos las riendas de su destino, pero de alguna manera antecede y protagoniza el acto de su propia constitución", señala Colom. La nación que antecede es la que denomina Colom, "nación étnica", mientras que la que se crea jurídicamente es la nación cívica. Me parece que esta distinción es fundamental para entender el proceso de independencias nacionales, pues todo movimiento de independencia apela a una nación histórica y culturalmente constituida que demanda su autodeterminación a un Estado que no la representa ni la reconoce. Pero una vez que el movimiento independentista triunfa, el nuevo poder soberano busca constituir una nueva nación, negando muchos rasgos de la que le antecedió. F. Xavier Guerra llama a la nación antecedente, "nación antigua", y a la constituida por el Estado, "nación moderna"; Bolívar Echeverría denomina a la primera "nación natural" y a la segunda "nación artificial". Yo utilizo los términos "nación cultural" y "nación estatal”, respectivamente. Más allá de los nombres lo importante es distinguir estas dos modalidades de naciones y, sobre todo, reconocer las tensiones e incluso conflictos agónicos que se establecen entre ellas, que son fundamentales para la comprensión de los movimientos de independencia y de constitución de los Estados nacionales. En este sentido, el artículo de Francisco Colom es una excelente discusión conceptual que sirve de marco articulador a los otros excelentes trabajos que se refieren a aspectos y procesos históricos específicos de las independencias iberoamericanas.

Precisamente, el artículo de Joaquín Rodríguez sobre Rusticatio mexicana del padre Landivar se enmarca en la elucidación del proceso de formación de la identidad nacional mexicana que antecede a la lucha de Independencia, que David Brading ha llamado "patriotismo criollo". Esta obra escrita por un jesuita expulso se ubica dentro de toda una serie de grandes textos que reivindica la grandeza de la naturaleza, historia, y cultura mexicana frente a las descalificaciones eurocéntricas del mundo iberoamericano, que se agudizan en el siglo XVIII y a las que Gerbi ha llamado "la disputa por el Nuevo Mundo". Antecede a Rusticatio la Biblioteca mexicana de Juan José Eguiara y Eguren, en la que se hace un recuento de los principales humanistas mexicanos del siglo XVI hasta mediados del siglo XVIII, como prueba contundente de la elevada cultura humanista mexicana, no novohispana. Don Ernesto de la Torre Villar considera que la Bibliotheca "trata de ser una demostración de la identidad mexicana a través del examen espiritual e intelectual que 
la conforman". ${ }^{1}$ Por otra parte, Rusticatio mexicana es un antecedente de otra gran obra de reivindicación de lo mexicano escrita por Francisco Javier Clavijero, también jesuita expulso, Historia antigua de México en la que debate con autores como Robertson, Buffon y De Pauw, que consideran que la naturaleza y las civilizaciones del Nuevo Mundo son, permítaseme la expresión, subdesarrolladas con relación al viejo continente.

En este marco, el análisis de la argumentación, principalmente retórica, que Joaquín Rodríguez hace de la obra de Landívar, permite considerarla como un texto eminentemente político en cuanto defiende la singularidad de la tierra y cultura mexicanas que no desmerece en nada a las europeas, y que tiene que ser apreciada y reconocida como tal. Así, al mismo tiempo que muestra lo propio de México, no Nueva España, reclama su reconocimiento por parte de los intelectuales europeos.

Finalmente, el tercer texto que conforma el dossier sobre Independencia del número 22 de Theoría, es "Lecturas de la Independencia en el exilio español del 39. José Gaos, Joaquín Xirau y Eduardo Nicol” de otro destacado filósofo español, Antolín Sánchez Cuervo, quien también ha realizado una encomiable labor de estudio y promoción de la filosofía iberoamericana en torno a la Independencia. En este artículo, con agudeza interpretativa, el autor muestra la preocupación de los filósofos del exilio español en México por integrar una filosofía iberoamericana con base en el pensamiento de destacados humanistas, cuyas obras tuvieron una significación política relevante en el proceso de independencia de México y de otras naciones latinoamericanas. Los tres autores analizados tienen el interés común de ahondar en la comprensión de obras claves de filosofía mexicana y, en general, iberoamericana que tuvieron una trascendencia política y social en la emancipación de estas naciones y de esta manera contribuyeron al desarrollo y consolidación de una tradición filosófica iberoamericana. También hay que destacar, en el caso de Gaos y Xirau, que sus principales trabajos sobre filosofía mexicana se escribieron entre 1942 y 1945 , lo cual muestra la prioridad que otorgaron en su quehacer intelectual a la filosofía mexicana en una época en la que eran pocos los filósofos, como Samuel Ramos, que se dedicaban a ello. A esta tarea habría que agregar otras figuras del exilio español como José M. Gallegos Rocafull, con su espléndido libro Pensamiento filosófico mexicano. Siglos XVI y XVII, publicado por la Universidad de México con motivo de su cuarto centenario, y Adolfo Sánchez Vázquez con su libro sobre la Ilustración y la Independencia, Rousseau en México. A todos ellos nuestra gratitud y reconocimiento.

${ }^{1}$ Ernesto de la Torre Villar, "Estudio introductorio a la antología de Juan José Eguiara y Eguren, Historia de los sabios mexicanos. México, UNAM, 1998, p. XXXII. 
De los tres autores tratados, José Gaos es por mucho quien más escribió sobre el tema, y, sobre todo, quien de manera más clara y enfática reconoce la fuerza transformadora del pensamiento hispanoamericano, considerándolo como "órgano principal de independencia y proceso de constitución de las naciones correspondientes”, además de reconocer el carácter ejemplar de los escritores americanos en la tradición filosófica hispanoamericana, caracterizada por su compromiso político y pedagógico, y de su preocupación por la forma literaria. Fue en México, al reflexionar sobre estos temas que Gaos, como otros filósofos de exilio español, se dio cuenta de la existencia de una tradición filosófica común del mundo iberoamericano, y que constituye una "potencia histórico cultural" de la cual han encontrado su fuerza espiritual de emancipación las naciones latinoamericanas, particularmente la mexicana. Antolín Sánchez Cuervo señala que con pesar, pero también con esperanzado optimismo, Gaos reconocía que España "era la única nación que de un común pasado imperial queda por hacerse independiente, no sólo espiritual, sino también políticamente".

Joaquín Xirau escribe sobre el tema en dos ensayos magistrales: "Humanismo español" (1942) e "Integración política de Iberoamérica" (1945). Al igual que Gaos, reconoce la existencia de una tradición humanista iberoamericana cuyos orígenes se remontan hasta el Medievo con Ramón Lull y Alfonso X el Sabio, continúa durante el Renacimiento con Vives, Vitoria y Bartolomé de las Casas, y resurge con Jovellanos y el conde de Arana, y en América con los líderes independentistas Hidalgo y Bolívar. Es esta tradición humanista emancipadora y centenaria la que le da unidad al mundo iberoamericano, opuesta a toda idea de imperio, superioridad o dominio, que afirma, por el contrario, "La convicción sinceramente sentida de que todos los valores -incluidos naturalmente los indígenas de América- nos pertenecen por igual a todos en la plenitud de su dignidad histórica". Esta unidad iberoamericana estaría fundada en una idea organicista de interdependencia igualitaria entre todas las naciones del mundo hispanoamericano de los dos hemisferios. Esta visión anticolonialista de Joaquín Xirau contrasta con la concepción de Eduardo Nicol, quien si bien también descubre en México la existencia de una tradición espiritual común, descubrimiento que lo distancia de filósofos españoles como Ortega y Gasset, quien "redescubrió Europa a costa de la pérdida de América”, no condena el colonialismo y la dominación de España sobre América, por considerarla un proyecto humanista que "no representó nunca una opresión del hombre sobre el hombre fundada en una discriminación racial", en palabras del propio Nicol. Esta justificación hispanista de la dominación colonial representa para Antolín Sánchez Cuervo obviar la "significación violenta de esta última, así como sus expresiones consumadas de inhumanidad". 
En suma, el artículo de Antolín Sánchez Cuervo resulta además de original, muy pertinente, pues nos ofrece un análisis detallado de las concepciones de tres grandes figuras del exilio español sobre la Independencia de México en el contexto de la filosofía y el mundo hispanoamericano.

En este número 23 se integran también tres artículos sobre la Independencia y otro sobre la Revolución de 1910.

El primero es de Bolívar Echeverría, profesor emérito de la UNAM, "El guadalupanismo y el ethos barroco en América". Este trabajo hay que ubicarlo dentro de la investigación de amplio aliento y gran originalidad sobre barroquismo y modernidad que desarrolló Bolívar Echeverría en los últimos años de su vida. Una de las tesis más importantes de esta amplia investigación es que el ethos barroco, como un principio estructurador del mundo de la vida en la modernidad capitalista, es ante todo un ethos histórico de resistencia al proceso de reproducción de valores de cambio, que de manera creciente excluye la importancia del disfrute de los valores de uso, de la forma "natural" de la vida social. Este ethos histórico de resistencia que pone en evidencia las contradicciones inherentes del capitalismo se opone radicalmente a otros ethe históricos de la modernidad capitalista, que como el "realista", que en términos weberianos corresponde a la "ética protestante", busca justificar y fomentar el desarrollo del capitalismo. Esta oposición entre un ethos afín a la reproducción del capital y otro de resistencia es de suma importancia, pues muestra que "vivir en y con el capitalismo puede ser algo más que vivir por y para el capitalismo". ${ }^{2}$

El ethos barroco tiene su expresión más profunda y radical en América Latina; precisamente por su carácter de pueblos conquistados y dominados son capaces de afirmar los restos de sus culturas originarias integrándolas en los códigos culturales de los vencedores y constituyendo así una nueva cultura, internamente contradictoria, donde coexisten elementos de civilizaciones disímbolas como la europea y las indígenas. En su libro, La modernidad de lo barroco, Bolívar desarrolla ampliamente esta tesis y la ejemplifica históricamente con el análisis de la figura histórica y mítica de Malintzin, el proyecto criollo y el proyecto jesuítico de civilización en la América ibérica. Ahora, Bolívar nos presenta una muy original interpretación del guadalupanismo como una expresión radicalmente barroca, en la que los indígenas vencidos se apropian de la religión católica y la transforman sincréticamente integrando en ella sus religiones politeístas originarias. Bolívar afirma que el exagerado (la exageración es un rasgo barroco) culto mariano del catolicismo guadalupano es en cierta manera una peculiar forma de idolatría: "La práctica del culto mariano implica en efecto una negación de la síntesis monoteísta que está en el dogma de la Santísima Trinidad, del Dios uno y trino, síntesis

${ }^{2}$ Bolívar Echeverría, La modernidad de lo barroco. México Era, 2005, p. 36. 
que es asumida pero no interiorizada. Lo que se asume realmente en su ligar es el orden de un panteón multipolar [...] una constelación 'politeísta' de configuración cambiante según los lugares de culto y las épocas”. Gracias a esta audacia barroca los indígenas vencidos preservan la autenticidad de sus culturas religiosas, transformándolas vía incorporación a la religión cristiana de los vencedores. Más adelante, escribe Bolívar que "es difícil encontrar un ejemplo más claro del comportamiento barroco, que se extenderá en las sociedades latinoamericanas desde el siglo XVII, que el de esta alteración de la religiosidad cristiana llevada a cabo por los indios guadalupanos de México en el siglo XVI". Con base en esta interpretación del guadalupanismo, Bolívar sostiene que "la identidad barroca que ha asumido una buena parte de la población latinoamericana a lo largo de considerables periodos de su historia [...] tiene su origen ya en el siglo XVI, en una forma de comportamiento inventada espontáneamente por los indios que sobrevivieron en la nuevas ciudades, después de que sus padres fueron vencidos en la conquista de América por la Europa ibérica”. Desde esta interpretación cobra pleno sentido la figura emblemática de la virgen de Guadalupe como símbolo y expresión de resistencia de una nación plural de indios, mestizos y criollos, durante el proceso de Independencia.

Por su parte, María del Carmen Rovira, pilar fundamental de la investigación y enseñanza de la filosofía en México, nos ofrece un interesante y revelador artículo sobre la formación intelectual de Miguel Hidalgo. Su trabajo "Presagios de independencia en el Seminario y Colegio de San Nicolás Obispo en Valladolid" centra su atención en la formación y magisterio de Miguel Hidalgo en dicho colegio, así como en la obra de su profesor José Pérez Calama. Carmen Rovira analiza primeramente la obra de este último, quien era doctor en Artes y Teología por la Universidad de Salamanca y llegó a la Nueva España hacia 1775 para impulsar toda una renovación educativa en teología y filosofía. Tanto él, como posteriormente Miguel Hidalgo, impulsaron el renacimiento de la teología positiva, cuyos orígenes se remontan a la escuela de Salamanca. Los teólogos de aquel entonces utilizaron esa nueva teología, apoyada en la historia, la filosofía antigua y medieval, así como en la filología, para cuestionar duramente las pretensiones de legitimidad de la guerra y el dominio español sobre América. Carmen Rovira subraya la impronta del nominalismo en la teología positiva, tradición filosófica que se opone a las categorías universales de la escolástica que desconocen la diversidad cultural e histórica propia de América y por ello resulta etnocéntrica. En particular la autora interpreta con sutileza la disertación de hidalgo "Sobre el verdadero método de estudiar teología" que escribió hacia 1785. Esta disertación, amen de otros escritos y estudios biográficos, le permiten a Carmen Rovira afirmar: "En Hidalgo se produjo primero una liberación de carácter intelectual, una rebeldía en un espacio tan importante como 
el teológico. Hidalgo no improvisó el movimiento de independencia. Por el contrario, su ideología se fue formando y consolidando a través de los años". La autora pone en evidencia que esa liberación y rebeldía intelectual no se produjo por influencia de las ideologías de las revoluciones atlánticas de Francia o de Estados Unidos, ni tampoco por influjo de la Ilustración europea, sino ante todo por la formación y cultivo de una tradición humanista propiamente iberoamericana cuyos orígenes se remontan a la escuela de Salamanca en el siglo XVI, y su desarrollo se radicaliza en México y en otros países latinoamericanos. En este sentido, Carmen Rovira coincide con las interpretaciones de Gaos y de Xirau que hemos visto anteriormente. En lo personal concuerdo plenamente con esta línea de interpretación que con otros argumentos he expuesto en el libro La persistencia del humanismo republicano en la formación de la nación y del Estado en México.

Luis Patiño Palafox presenta su artículo "Lucas Alamán. La conquista de México y el origen de una nueva nación”. En este trabajo hace un interesante análisis de la interpretación de la revolución de Independencia, por parte de unos de los intelectuales y políticos más destacados de la primera mitad del siglo XIX, Lucas Alamán. Lo más interesante de este trabajo consiste en la comparación entre el pensamiento histórico y filosófico de Lucas Alamán en torno a la Conquista, la Colonia y la Independencia con la visión de otro gran escritor y político de su época, Carlos María Bustamante, quien trabajó al lado de Morelos durante la guerra de Independencia y tuvo una gran influencia intelectual en el movimiento insurgente y en los primeros años del México independiente. Atinadamente, Luis A. Patiño Palafox ubica a Carlos María Bustamante como un humanista impulsor del indigenismo histórico, crítico radical de la dominación española en América, lo cual marca un hondo contraste con la visión prohispanista de Lucas Alamán, quien consideraba a la Conquista y a la dominación colonial como un acontecimiento providencial y civilizador. Desde esta perspectiva prohispanista, la Independencia iniciada por Hidalgo y Morelos resultaba ser una afronta violenta y sin sentido, que amenazaba con destruir mucho de lo logrado durante el periodo colonial. Esta imagen de los insurgentes contrasta con la elogiosa caracterización de Iturbide como el verdadero héroe de la Independencia. Todo lo contrario sostiene Carlos María Bustamante, para quien las figuras de Morelos y de Hidalgo representan el resurgimiento de una nación conquistada y vejada por los españoles desde 300 años atrás, que reclama su libertad y soberanía perdida y así romper definitivamente con las cadenas de la esclavitud que se le impusieron a México-Tenochtitlan en 1521. Es importante señalar que estas dos interpretaciones de la Colonia y la Independencia se manifestaron también en el seno mismo de la tradición liberal. Por ejemplo, José María Luis Mora y Lorenzo de Zavala sostienen una visión muy afín a la de Lucas Alamán, mientras que 
republicanos liberales como fray Servando Teresa de Mier coincidirían plenamente con la visión de Bustamante. Como hace notar José María Vigil, esta confrontación de dos interpretaciones de la Conquista, la Colonia y la Independencia constituyen uno de los principales traumas en la formación de una conciencia nacional que perduró a lo largo del siglo XIX y, sin lugar a dudas, también en el Xx. Intelectuales del tamaño de José Vasconcelos sostienen una visión de la historia de México semejante a la de Lucas Alamán, mientras que antropólogos de la trascendencia de Manuel Gamio defenderían en mucho la visión de Carlos María Bustamante. Incluso, en los filósofos del exilio español que analiza Antolín Sánchez Cuervo, podemos encontrar coincidencias relevantes de Eduardo Nicol con la visión de Alamán sobre la Colonia y cercanías interpretativas de Joaquín Xirau con la visión anticolonialista de Carlos María Bustamante. La persistencia de este conflicto en la conciencia nacional hasta nuestros días la ha puesto en evidencia Miguel León-Portilla en su más reciente libro sobre la Independencia, la Reforma y la Revolución, denunciando, en un tono semejante al de Carlos María Bustamante, la injusticia causada sobre los pueblos indígenas, no sólo por la dominación colonial, sino también por el Estado mexicano. En suma, el artículo de Luis Patiño Palafox no sólo resulta ser un interesante análisis sobre confrontaciones de interpretación de los grandes momentos de la historia nacional, sino también resulta ser una reflexión sobre los dilemas y traumas de la conciencia nacional que han persistido por siglos hasta nuestros días.

En suma, no ha lugar a festejar doscientos años de Independencia, ni cien años de Revolución, sino más bien estas conmemoraciones son una oportunidad para reflexionar crítica y propositivamente sobre las promesas incumplidas de los dos más importantes acontecimientos de nuestra historia nacional y las alternativas que se pueden vislumbrar para hacerlas realidad. Si, como se ha puesto en evidencia con relación a la Independencia, el pensamiento filosófico iberoamericano tuvo un papel preponderante en la formación de una conciencia emancipadora, a doscientos años de la Independencia y cien de la Revolución mexicana - la primera revolución social del siglo xx- la filosofía debe también tener un papel central en la revisión crítica de por qué no hemos alcanzado los ideales y valores principales como nación. Pero hoy en día esta tarea no será realizada sólo por la filosofía iberoamericana, sino que tiene que vincularse estrechamente y con equidad al pensamiento de los pueblos indígenas del continente americano y particularmente de México, pues ellos han sido los primeros en levantar la voz y rebelarse contra la profunda injusticia social de nuestros países; contra el colonialismo interno y la explotación externa, y contra la ausencia de democracia y de reconocimiento de la diversidad cultural. Estamos pues, ante el reto de una profunda transformación de la filosofía iberoamericana en un sentido multicultural, 
republicano y emancipador, que nos oriente hacia la realización de los ideales de autodeterminación, interdependencia, democracia, justicia y bienestar, ideales por los que hace más de doscientos años se iniciaron los movimientos de independencia iberoamericanos.

Lo que sí celebramos es que los artículos sobre la Independencia y la Revolución mexicanas publicados en éste y el anterior número de Theoría, promuevan reflexiones filosóficas de amplia potencia crítica a la realidad social, politica y cultural, particularmente de nuestro país y del mundo iberoamericano. Con ello se cumple con el propósito fundamental de Theoría que manifestamos desde el primer número (19) a cargo del actual Consejo de Redacción. 